\title{
The Flipped Classroom: An Innovative Approach to Medical Education in Ophthalmology
}

\author{
Chris R. Alabiad, MD ${ }^{1}$ Kevin J. Moore, MD, $\mathrm{MPH}^{2}$ \\ Alex J. Mechaber, MD ${ }^{1}$ Carol L. Karp, MD ${ }^{1}$ \\ ${ }^{1}$ Department of Clinical Ophthalmology, Miller School of Medicine, \\ University of Miami, Miami, Florida \\ 2 Department of Dermatology, Harvard Medical School, Boston, \\ Massachusetts \\ ${ }^{3}$ Department of Anesthesia, Medical University of South Carolina, \\ Charleston, South Carolina
}

\author{
David P. Green, EdD ${ }^{1} \quad$ Matthew Kofoed, MD ${ }^{3}$
}

J Acad Ophthalmol 2020;12:e96-e103.

\begin{abstract}
Address for correspondence Chris R. Alabiad, MD, Department of Clinical Ophthalmology, Bascom Palmer Eye Institute, University of Miami, Miller School of Medicine, 900 NW 17th Street, Miami, FL 33136 (e-mail: calabiad@med.miami.edu).
\end{abstract}

\begin{abstract}
Keywords

- flipped classroom

- medical education

- ophthalmology

- mentorship

Objective The aim of the study is to report the creation of a flipped ophthalmology course and preclinical medical student perceptions and knowledge gains before and after a flipped ophthalmology course.

Design The form of the study discussed is an observational study.

Subjects The subjects involved in the study are second-year (U.S.) United States medical students at the University of Miami, Miller School of Medicine $(n=401)$.

Methods Second-year medical students participated in a 1-week "flipped classroom" ophthalmology course geared toward primary care providers at the University of Miami, Miller School of Medicine. Eleven hours of traditional classroom lectures were condensed into 4.5 hours of short videos with self-assessment quizzes, small group discussions, and a large group case-based discussion. Fifty-seven short videos ( $<9$ minutes) focused on major ophthalmology topics and common conditions were viewed by the students at their leisure. Students completed a pre- and post-course evaluation on their perceptions and opinions of the flipped classroom approach. Final exam scores in the flipped classroom cohort were compared with the final exam scores in the traditional didactic format used in years prior.

Main Outcome Measures The main outcome measures include: student final exam performance; student satisfaction, opinions, and perceptions.

Results Over the course of 2 years, 401 second-year U.S. medical students participated in the flipped classroom ophthalmology course. The majority of students enjoyed the flipped classroom experience $(75.3 \%)$ and expressed interest in using the approach for future lessons (74.6\%). The flipped classroom videos were preferred to live lectures (61.2\%). Over $90 \%$ of students stated the self-assessment quizzes were useful, $79 \%$ reported that the small group discussions were an effective way to apply knowledge, and $76 \%$ cited the large group case-based discussion as useful. Pre-course knowledge assessment scores averaged $48 \%$. Final examination scores in the flipped group (average \pm standard deviation $[S D]=92.1 \% \pm 6.1$ ) were comparable to that of the traditional group when evaluating identical questions (average $\pm S D=91.7 \% \pm 5.54$ ), $p=0.34$.
\end{abstract}

received

December 9, 2019 accepted after revision May 18, 2020
DOI https://doi.org/

10.1055/s-0040-1713681. ISSN 2475-4757.
Copyright $\odot 2020$ by Thieme Medical

Publishers, Inc., 333 Seventh Avenue, New York, NY 10001, USA. Tel: +1(212) 760-0888.
License terms

$(\circledast) \Theta \circledast$ 
Conclusion The flipped classroom approach proved to be a well-received and successful approach to preclinical medical education for ophthalmology. This was achieved using $35 \%$ less course time than our traditional course. This innovative approach has potential for expansion to other medical schools, medical education abroad, and for other medical school modules.

Preclinical medical education is experiencing a paradigm shift. ${ }^{1}$ With the rise of technology and rapid growth of medical information, a need for innovative approaches to medical education has arisen. ${ }^{2,3}$ Computer-assisted learning environments, which promote active-learning approaches, are supplementing (and in some cases replacing) traditional lectures. ${ }^{4,5}$ Simultaneously, physicians in-training requires skills development in other arenas that cannot generally be accommodated within a lecture environment (teamwork, clinical reasoning, problem solving, and mentorship). These demands have created opportunities to formally evaluate nontraditional approaches to preclinical medical education, such as the learner-centered flipped classroom approach. The expanding preclinical medical curriculum has also limited the time dedicated to ophthalmology education in medical schools across the United States. ${ }^{6-8}$ This has been further hampered by a shift at many medical schools away from a 2-year preclinical curriculum in favor for a shorter period of time (e.g., 18 months).

The "flipped classroom" is an inventive educational approach which uses short self-administered videos to educate the students, replacing traditional lectures. ${ }^{2}$ Limited class time focuses on active, problem-based learning. Research has shown positive results for the flipped classroom method, having successful implementation in other preclinical subjects such as nephrology, pulmonology, and cardiology among others. ${ }^{9,10}$ Given the need for an efficient and effective approach for ophthalmology education, a flipped classroom approach may offer a solution to reintroduce ophthalmology into the preclinical curriculum in medical schools.

While literature detailing the use of a flipped classroom approach for preclinical medical school education in ophthalmology exists, ${ }^{11-14}$ these reports utilize the flipped classroom for a small component of the course (e.g., ocular trauma or glaucoma) or deliver pre-classroom content using conventional methods (previously taped lecture videos and power points) for review prior to case/problem-based learning in class.

This paper reports and describes the implementation and delivery of a flipped classroom methodology for ophthalmology. This was utilized for 2 consecutive years of a flipped classroom approach in a sophomore medical school 1-week course. The course combined a technology-enriched flipped classroom learning environment with active face to face teaching (blended classroom). The purpose of this study was: (1) to determine if knowledge acquisition differed between the traditional approach versus the flipped ap- proach as measured by final examination performance and (2) to assess the students' perceptions of the flipped approach both prior to and after course completion. This is the first report describing the implementation and delivery of a comprehensive flipped/blended ophthalmology course.

\section{Materials and Methods}

This study was performed after obtaining an exemption from the University of Miami Institutional Review Board and the research adhered to tenets of the Declaration of Helsinki. The authors of this manuscript do not have any financial disclosures related to the content of the material nor conflicts of interest. This study has been funded by NIH Center Core Grant P30EY014801, RPB Unrestricted Award and Career Development Awards, Department of Defense (DODGrant\#W81XWH-09-1-0675), The Ronald and Alicia Lepke Grant, The Lee and Claire Hager Grant, The H. Scott Huizenga Grant, The Grant and Diana Stanton-Thornbrough Grant, The Robert Baer Family Grant, The Mark Feldberg and Emilyn Page Grant, The Jose Ferreira de Melo Grant, The Michele and Ted Kaplan Grant, and the Richard Azar Family Grant (Dr. Karp/institutional grants).

\section{Course Design and Overview}

The flipped classroom course ( 4.5 hours video +4 hours cases) replaced a traditional didactic curriculum (11-onehour lectures +2 hours cases), a $35 \%$ reduction in course

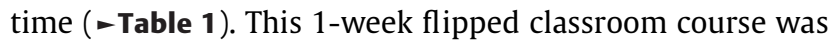
designed to provide sophomore medical students a fundamental knowledge of ophthalmology expected of a primary care provider. This included a broad overview of basic epidemiology, pathophysiology, diagnoses, and treatments in ophthalmology based on the most current recommendations of the International Council of Ophthalmology. ${ }^{15} \mathrm{Re}-$ dundant content and gaps in the traditional course curriculum were addressed in creating the new course curriculum (-Table 2 ).

The course design included self-administered short videos, one large group session, and one small group session. The flipped classroom design was implemented to secondyear medical students for two consecutive years. The module was delivered via similar server interfaces, Blackboard (www.blackboard.com) the first year and Canvas (www. canvaslms.com) the second year. All videos and materials were posted and available on the Blackboard/Canvas course sites, and students were given 2 days of self-study time to review video and supplemental content before each group 
Table 1 Course structure and design: flipped classroom versus traditional classroom for ophthalmology education

\begin{tabular}{|c|c|c|c|c|}
\hline & Educational intervention & Time & $\begin{array}{l}\text { Learner-centered } \\
\text { environment }\end{array}$ & What learners do \\
\hline \multirow[t]{3}{*}{$\begin{array}{l}\text { Traditional } \\
\text { classroom }\end{array}$} & - 11 live lectures & $11 \mathrm{~h}$ & No & $\begin{array}{l}\text { Passively listen to faculty-directed } \\
\text { presentations; take notes. }\end{array}$ \\
\hline & $\begin{array}{l}\text { - Small group discussion } \\
\text { (day } 4 \text { of course) }\end{array}$ & $2 \mathrm{~h}$ & Yes & $\begin{array}{l}\text { Collaboratively work through } \\
\text { faculty-directed case studies. }\end{array}$ \\
\hline & Total time & $13 \mathrm{~h}$ & & \\
\hline \multirow[t]{4}{*}{$\begin{array}{l}\text { Flipped } \\
\text { classroom }\end{array}$} & $\begin{array}{l}\text { - Online learning modules featuring } \\
\text { short "Khan Academy" style videos } \\
\text { ( } 2 \mathrm{~d} \text { of self-study between group } \\
\text { sessions). }\end{array}$ & $4.5 \mathrm{~h}$ & Yes & $\begin{array}{l}\text { Access online course content before } \\
\text { face-to-face sessions via a learning } \\
\text { management system with learning } \\
\text { objectives, supplemental resources, and } \\
\text { self-assessment knowledge-check } \\
\text { questions. }\end{array}$ \\
\hline & $\begin{array}{l}\text { - Small group discussions } \\
\text { (day } 3 \text { of course). }\end{array}$ & $2 \mathrm{~h}$ & Yes & $\begin{array}{l}\text { Collaboratively work through } \\
\text { faculty-directed case studies. }\end{array}$ \\
\hline & $\begin{array}{l}\text { - Large group discussions and debriefs } \\
\text { (day } 5 \text { of course). }\end{array}$ & $2 \mathrm{~h}$ & Yes & $\begin{array}{l}\text { Collaboratively work through } \\
\text { faculty-directed case studies. }\end{array}$ \\
\hline & Total time & $8.5 \mathrm{~h}$ & & \\
\hline
\end{tabular}

Table 2 Key steps to creation of flipped/blended classroom learning environment

\begin{tabular}{|c|c|}
\hline Steps & Specific tasks \\
\hline $\begin{array}{l}\text { 1. Curriculum creation } \\
\text { Human capital: } \\
\text { - Faculty member }\end{array}$ & $\begin{array}{l}\text { - Reference guidelines (AAMC, specialty specific white paper, ICO, etc.). } \\
\text { - Identify redundancy, gaps, outdated information in old curriculum. } \\
\text { - Creation of objectives, outlines, course content, image repository of key } \\
\text { ophthalmic findings. } \\
\text { - Creation of cases for in class sessions. } \\
\text { - Creation of assessment questions. }\end{array}$ \\
\hline $\begin{array}{l}\text { 2. "Khan Academy" Style videos } \\
\text { Human capital: } \\
\text { - Faculty member } \\
\text { - Video editor }\end{array}$ & $\begin{array}{l}\text { - Creation of scripts. } \\
\text { - Review of script accuracy with content experts. } \\
\text { - Creation of captivating images/cartoons (Camtasia). } \\
\text { - Creation of short videos (Sketchbook Pro). }\end{array}$ \\
\hline $\begin{array}{l}\text { 3. Learning management system } \\
\text { Human capital: } \\
\text { - Faculty member. } \\
\text { - Computer specialist/Course } \\
\text { platform designer }\end{array}$ & $\begin{array}{l}\text { - Creation of content modules. } \\
\text { - Upload objectives, videos, outlines, self-assessment questions, supplementary } \\
\text { materials, images, materials/resources for face to face sessions. } \\
\text { - Creation of discussion board. } \\
\text { - Student access to pre- and post-course surveys and pre-course knowledge } \\
\text { assessments. }\end{array}$ \\
\hline
\end{tabular}

Abbreviations: AAMC, Association of American Medical Colleges; ICO, International Council of Ophthalmology.

session. All group sessions were interactive, and student participation and collaboration were encouraged.

\section{Short Educational Videos}

In the flipped classroom approach, several short (2-9 minutes) videos replaced traditional ( 1 hour) lectures for information delivery. The short videos were designed in Khan Academy (www.khanacademy.org) style with a black background, written text, relevant images, and a voice-over narration explaining each topic (-Fig. 1A,B). The drawings/illustrations for the videos were created using Camtasia software and the videos using Sketchbook Pro software. The authors worked closely with a medical education fellow to design and to construct the short videos according to the scripts described above (-Table 2). Fifty-seven short videos featured twelve major units: oculoplastic, pediatric ophthalmology, neuro-ophthal- mology, conjunctiva, glaucoma, cornea, uvea, lens, retina, ocular trauma, ocular oncology, and the eye in systemic disease. In total, video time summed to approximately 4.5 hours. An example of a video can be seen by accessing the following link: https://vib.by/v/X1WX5x0z

A computer specialist/course platform designer was essential to package each module to include all learning materials for easy access by students. Each module focused on specific learning objectives. The authors (C.R.A. and C.L.K.) worked closely with a medical education fellow to design and to construct the short videos. The videos were reviewed and revised by the authors at all levels of development and design. Each video included embedded questions (2-8 questions per module) to assess student understanding following the short videos. These questions highlighted the most important learning points of the unit. 

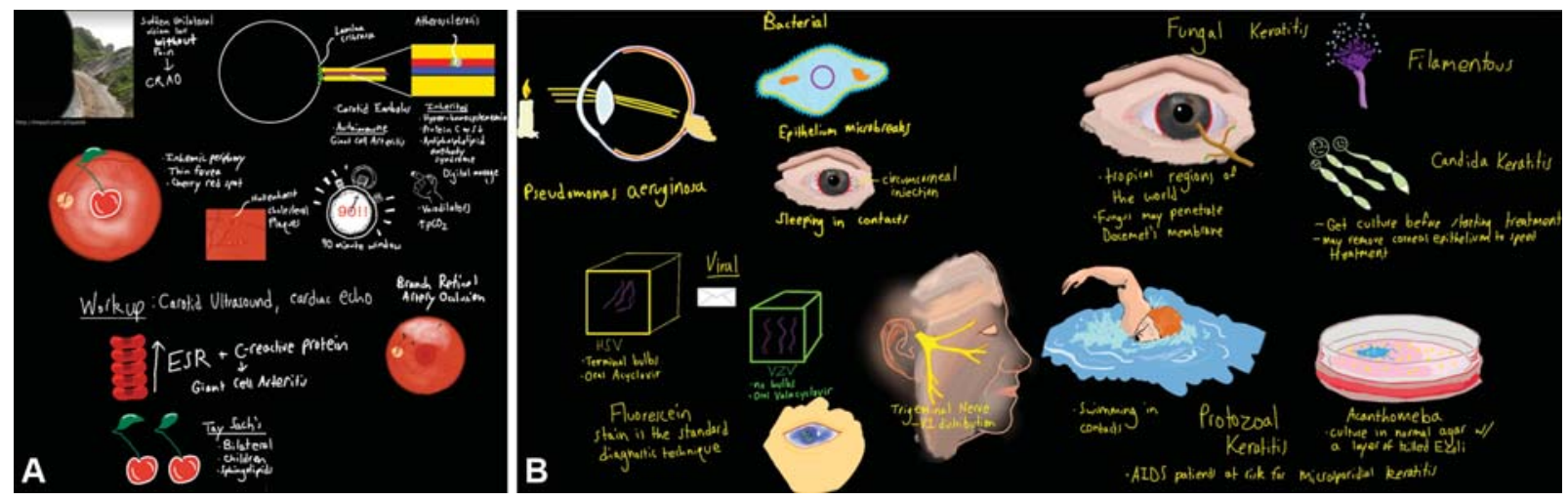

Fig. 1 Flipped classroom short video examples. Screen shot for central retinal artery occlusion (A) and infectious keratitis (B).

\section{Small and Large Group Sessions}

Students participated in one small group (approximately 15 students) session and one large group session (approximately 65 students). The large group session and small group session each lasted 2-hours and each covered six cases. Course directors drafted the cases to focus on common ophthalmologic conditions encountered in the primary care setting, emphasizing the content from the videos. Twelve faculty members participated as facilitators for the small group session, and three faculty members served as facilitators for the large group session. All sessions were interactive, and student participation and collaboration were encouraged. Audience response question technology was incorporated to the large group session to facilitate student participation and to help facilitators gauge whether the students were properly grasping concepts.

\section{Student Assessment and Performance}

Through the online site, students completed a pre-course knowledge assessment (59 questions) and a post-course knowledge assessment (59 questions). These questions aligned with the objectives from each of the 12 major units. At the end of the course, students sat for a 50-question multiple choice final exam. Final exam scores were compared among 4 years of classes-2 years of the flipped classroom and 2 years prior to the flipped classroom implementation (traditional lectures). Though exams were not identical over all 4 years, 72\% (36 exam questions) were almost identical over all 4 years. An analysis was performed on these identical questions and overall final exam performance across both cohorts.

\section{Student Acceptability and Satisfaction}

Students completed pre-course and post-course surveys on their opinions, perceptions, and satisfaction with the flipped classroom course. The pre-course survey included 52-items and featured questions on self-reported baseline ophthalmology knowledge, past flipped classroom participation, and anticipatory enjoyment and knowledge gains with the flipped classroom method. The post-course survey (65 questions) included questions on overall impression of the flipped classroom approach, opinions of the specific aspects of the design (i.e., short videos, small group sessions, large group sessions), and self-reported knowledge gain and comfort in ophthalmology.

\section{Additional Resources}

The online course sites also included an "Image Repository" created by the course directors. This repository included key clinical images and summary cartoons from each of the short videos. The Image Repository also contained supplementary figures and cartoons for students to study certain topics of interest in more depth. Students also had access to video outlines created by the course directors to aid in following the video content and to allow them to write notes from the videos.

\section{Statistical Analysis}

Descriptive statistics were tabulated to compare across and within subgroups. Continuous variables were presented with mean, standard deviation, minimum, and maximum. Student $t$-tests were used to compare means of continuous variables with a significance level of $\alpha=0.05$. All statistical analyses were completed using SAS v.9.4 (SAS Institute, Cary, $\mathrm{NC}$ ). The Institutional Review Board provided an exemption for this study as all data remained confidential and anonymous.

\section{Results}

In total, 401 medical students participated in the flipped classroom ophthalmology course over a 2-year period. The mean student MCAT score and mean undergraduate GPA (grade point average) were comparable between the traditional classroom years and the flipped classroom years.

\section{Pre-Course Student Perceptions and Opinions}

Two-hundred and ninety-two students completed the precourse perceptions survey ( $74.3 \%$ participation rate). In the pre-course survey, $97.6 \%$ responded that they expected to enjoy the flipped classroom, and approximately $96.0 \%$ anticipated learning moderate amount or greater with the new flipped classroom approach. A minority of students had taken a flipped classroom before (30.5\%), and among those students, the majority had enjoyed their previous experience with the flipped classroom approach (85.3\%). 


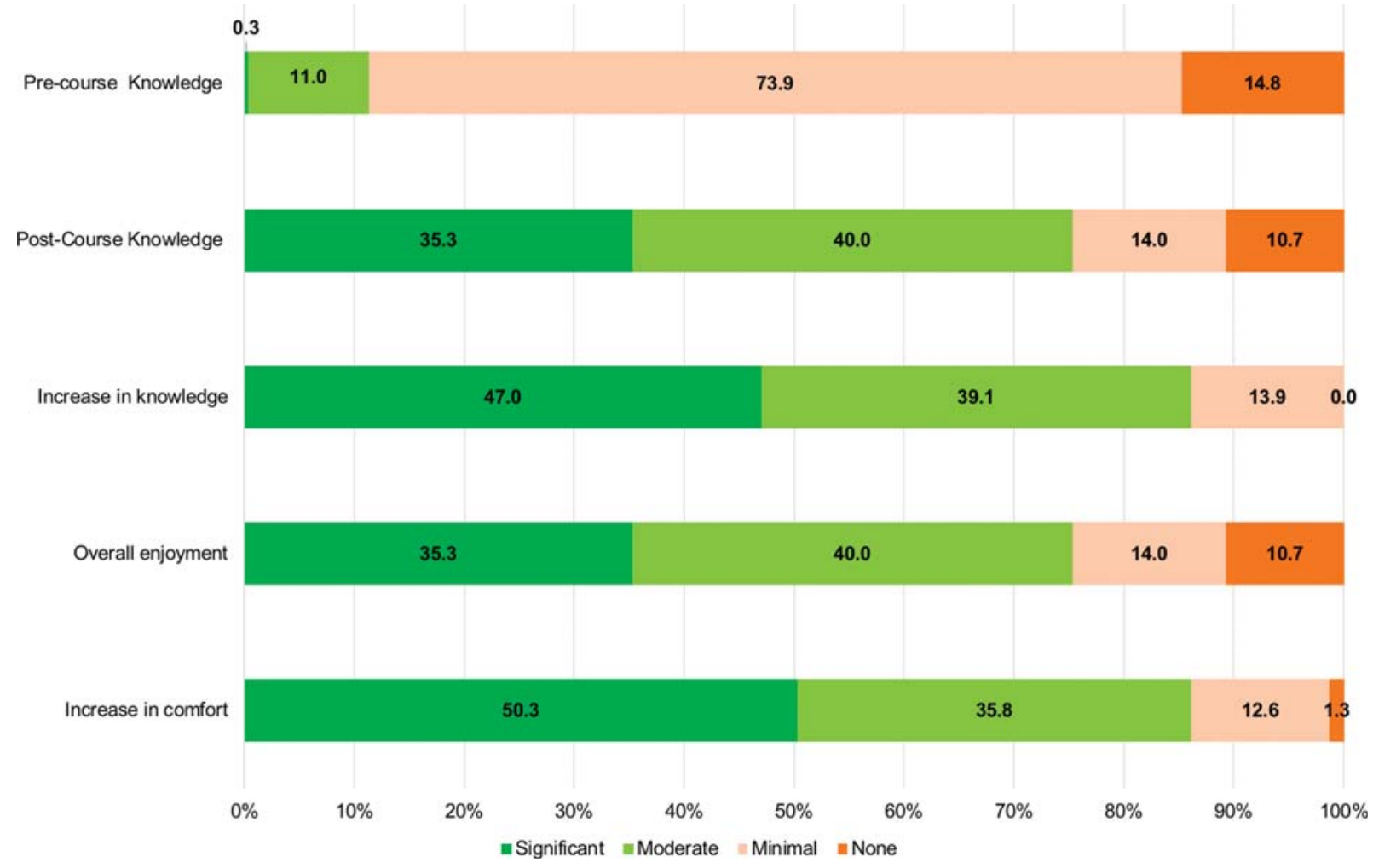

Fig. 2 Self-reported student perceptions and opinions of the flipped classroom approach $(n=152)$.

\section{Pre- and Post-Course Student Knowledge}

A total of 181 students completed the pre-course knowledge assessment. The average score of those who completed the exam was $48.1 \%$ (standard deviation $[\mathrm{SD}] \pm 12.6$; range $15-98 \%)$. The large majority ( $88.7 \%$ ) of students who completed the pre-course perceptions survey reported that they had no knowledge or minimal knowledge of ophthalmology. Following completion of the flipped classroom course, $152 \mathrm{stu}-$ dents of the 401 students completed the post-course perceptions survey (37.9\% participation rate). The majority of students reported moderate or significant enjoyment with the flipped classroom experience (75.3\%), and the majority of students stated that they were in favor of using of the flipped classroom approach for future lessons (74.6\%) (- Figs. 2 and 3 ).

In terms of the self-assessment quizzes, the majority of students agreed or strongly agreed that the self-assessment quizzes were useful (83.1\%), accurately addressed short video content (79.0\%), and reflected understanding of short video content (77.0\%). Similarly, for the faculty-led large and small group sessions the majority of students agreed that the sessions were an effective way to apply knowledge (76.9\%), reinforced important content (74.3\%), and related the academic content to real-world scenarios (80.3\%).

\section{Post-Course Student Knowledge}

Over $85 \%$ of all students stated that their comfort with ophthalmology had increased moderately or significantly after the flipped classroom experience. Self-reported ophthalmology knowledge following the flipped classroom course increased as well with $75.3 \%$ of students expressing moderate or significant ophthalmology knowledge.

\section{Traditional Classroom versus Flipped Classroom Final Exam Performance}

The class mean final exam score for both years of the flipped classroom approach was higher than the 2 years of traditional classroom $(p<0.01 ;-$ Table 3$)$. The mean final exam score for the 2 years flipped classroom was $93.5( \pm 5.1)$, whereas the mean final score for the two previous years of traditional classroom was $90.3( \pm 5.7)$. An analysis of the performance on the 36 questions consistent across all examinations, revealed no significant difference between the students in the traditional group (average $\pm \mathrm{SD}=91.7 \% \pm 5.54$ ) versus the flipped group (average $\pm \mathrm{SD}=92.1 \% \pm 6.1$ ), $p=0.34$.

\section{Discussion}

Our results demonstrate that the flipped classroom educational approach is an effective and well received modality for medical education in ophthalmology. Performance on the pre-course knowledge assessment suggests that student baseline knowledge of ophthalmology is low, as expected, emphasizing the need for effective and efficient ophthalmic education. Performance on the final examination suggest that the flipped classroom technique allowed for mastery of content, similar to that noted during the traditional lecture style course. This was achieved with 35\% decreased course time. Furthermore, students reported a positive and enjoyable learning experience with reduced learning time.

\section{Positive Student Attitudes and Reception}

The flipped classroom approach was well-anticipated and well-received by the student population. The pre-course 


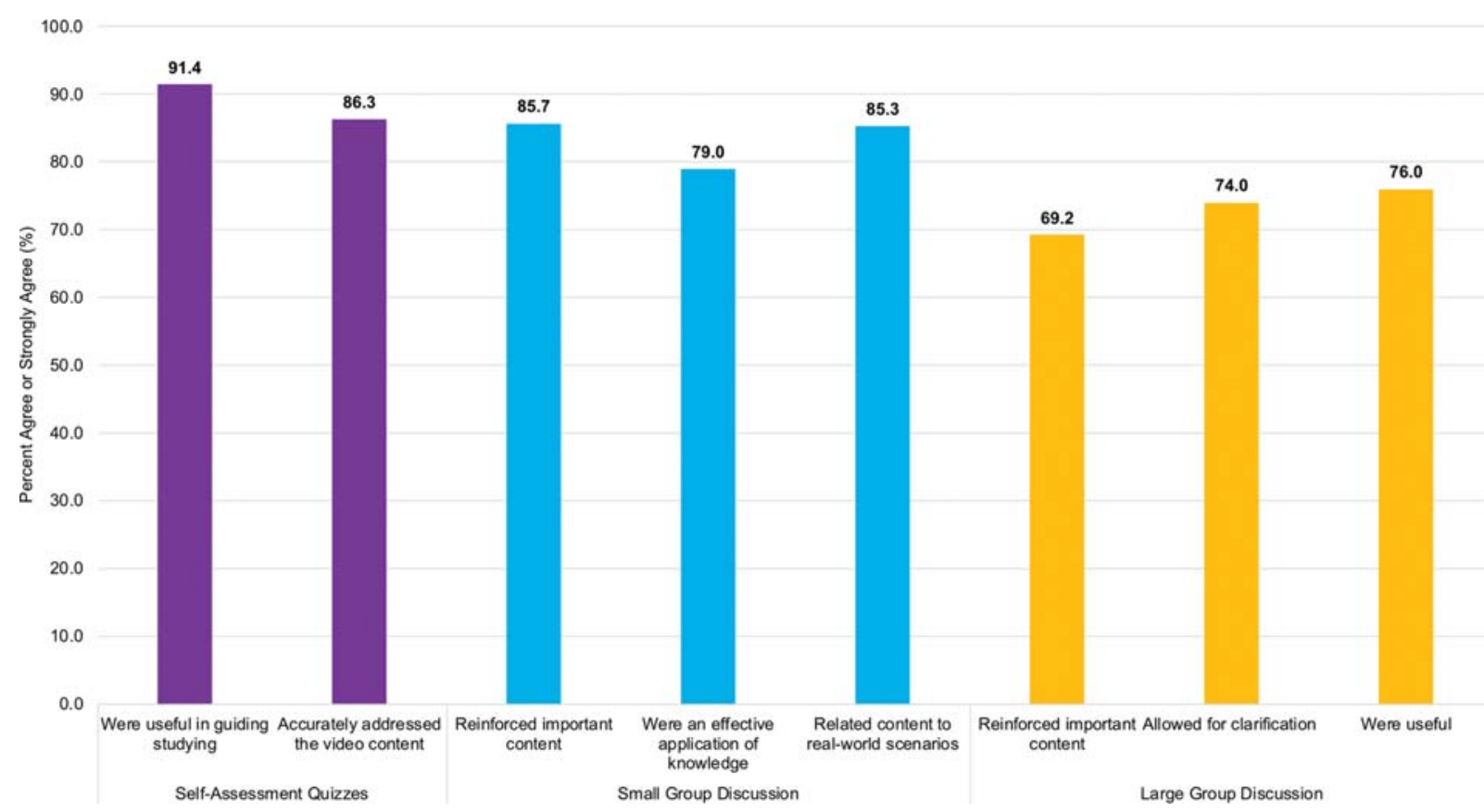

Fig. 3 Student acceptability and opinions of flipped classroom approach components-Self-assessment quizzes, small group discussions, and large group discussions $(n=145)$.

Table 3 Ophthalmology pre-course knowledge assessment and final exam performance

\begin{tabular}{|c|c|c|c|}
\hline \multicolumn{4}{|c|}{ Pre-course knowledge check (59 questions) } \\
\hline & & $\begin{array}{l}\text { Flipped } \\
\text { classroom }\end{array}$ & \\
\hline$n$ & & 181 & \\
\hline $\begin{array}{l}\text { Mean } \\
( \pm S D)\end{array}$ & & $48.1 \%( \pm 12.6)$ & \\
\hline Range & & $15.3 \%-98.3 \%$ & \\
\hline \multicolumn{4}{|c|}{ Shared questions among all exams (36 questions) } \\
\hline & $\begin{array}{l}\text { Traditional } \\
\text { classroom }\end{array}$ & $\begin{array}{l}\text { Flipped } \\
\text { classroom }\end{array}$ & $p$-Value ${ }^{a}$ \\
\hline$n$ & 393 & 401 & \\
\hline $\begin{array}{l}\text { Mean } \\
( \pm S D)\end{array}$ & $91.7 \%( \pm 5.5)$ & $92.1 \%( \pm 6.1)$ & $=0.34$ \\
\hline Range & $61.1-100.0 \%$ & $69.4-100.0 \%$ & \\
\hline \multicolumn{4}{|c|}{ Full final exam score (50 questions) } \\
\hline & $\begin{array}{l}\text { Traditional } \\
\text { classroom }\end{array}$ & $\begin{array}{l}\begin{array}{l}\text { Flipped } \\
\text { classroom }\end{array} \\
\end{array}$ & $p$-Value ${ }^{\mathrm{a}}$ \\
\hline$n$ & 393 & 401 & \\
\hline $\begin{array}{l}\text { Mean } \\
( \pm S D)\end{array}$ & $89.82 \%( \pm 5.8)$ & $93.0 \%( \pm 5.4)$ & $<0.01$ \\
\hline Range & $64.0-100.0 \%$ & $66.0-100.0 \%$ & \\
\hline
\end{tabular}

aSignificance level at $\alpha=0.05$.

attitudes were positive with the clear majority of students anticipating enjoyment and improved learning with the new approach. The post-course reflections remained positive with the majority of students stating that they enjoyed the flipped classroom experience (75.3\%). Further, student expectations with regards to anticipated knowledge gains were exceeded. Prior to taking the course, $41.0 \%$ anticipated to learn a "significant" amount, and the post-course evaluation showed that $47.0 \%$ of students reported learning a "significant" amount. In addition, the majority of students reported that they preferred the flipped classroom approach compared with the traditional classroom lecture approach (61.2\%). The learner also benefits from a time advantage. In this particular course, students watch 4.5 hours of video and participate in 4 hours of group learning as compared with the traditional classroom approach where the learners were present for 11 hours of lecture and 2 hours of group learning.

\section{Focus on Active Learning}

Recent education research has supported the use of active learning methods to maximize student performance and participation. ${ }^{16}$ As in this study, the flipped classroom method allows for class time with active learning instead of passive learning through traditional live lectures. ${ }^{5}$ The required small and large group sessions complement the short videos to allow students to actively apply lessons and concepts learned. This is facilitated by the fact that the students enter the classroom with a higher baseline level of understanding of the material. This also enables the students to build on basic concepts in class and ask higher order questions pertaining to the material. Review of the post-module practice questions prior to the group sessions allows the group facilitators to identify concepts that students struggled to understand through their own self-study. Similarly, the use of audience response question technology built in to the case presentation during the large group session allows the facilitator to further comprehend knowledge gaps among the audience. The small group session allows the facilitator to identify individual students who 
are struggling, allowing an opportunity to establish additional lines of academic support for the student as needed. Studies comparing traditional lecture learning to active learning applications have shown superiority in student acceptance and performance. ${ }^{17,18}$

Problem-based learning in medical schools has shown to have positive effects on physician competency beyond medical school. ${ }^{19,20}$ The potential to maximize active learning under faculty guidance adds to the strength of the flipped classroom approach.

\section{Standardizing Ophthalmology Medical Education}

Beyond the improved test scores and positive student attitudes toward the new course design, the flipped classroom offers an opportunity to standardize ophthalmology medical education across medical schools and other health professional schools both nationally and internationally. Given the rapid pace of scientific discovery, there is a growing need to standardize medical education to emphasize the most important and updated points. ${ }^{21}$ Albert and Bartley emphasized the need to standardize ophthalmology education due to the exponential growth in scientific knowledge and the importance of basic ophthalmology education among all physicians. ${ }^{22}$ With an online platform and fewer required faculty resources, the flipped classroom curriculum affords a greater ease of standardization for ophthalmology medical education.

\section{Expanding the Use of Flipped Classroom}

In addition to standardization of ophthalmology education, this flipped classroom approach has potential for implementation in low-resource settings. Research shows that there are significant gaps in medical and ophthalmic education in countries abroad. ${ }^{23,24}$ Basic ophthalmologic knowledge is critical for all physicians and health professionals. ${ }^{25}$ The short videos provide the primary means for information delivery in the flipped classroom model. Use of these videos can give health providers a basic introduction into ophthalmologic conditions and treatments. Given the importance of basic ophthalmologic education, the flipped classroom design may allow for greater dissemination of standardized ophthalmologic education internationally and among physicians in all specialties of practice. The content is also digestible enough to use as education tools for patients who are interested in having a deeper understanding of their ophthalmic condition.

\section{Faculty Demand}

One of the major advantages of the flipped classroom approach is the reduced demand on ophthalmology faculty to prepare and deliver lectures. It is important to recognize that one option to reduce faculty demand in medical schools is prerecorded lectures; however, in the post-course survey, the majority of students (72.9\%) stated that they prefer the flipped classroom short videos to recorded lectures. Further, the flipped classroom approach maximizes face to face faculty time with active, case-based learning rather than passive lectures. The group learning environment does call for a robust faculty presence, a demand that increases with larger medical school classes and smaller groups. This also promotes an environment conducive to future mentorship between student and learner. Faculty facilitators are also able to encourage team building strategies and observe learners' clinical reasoning skills and social interactions, components that are critical to clinical medicine. The authors used ophthalmology faculty, ophthalmology fellows, and senior ophthalmology residents for the group sessions; however, not all medical schools have enough ophthalmology faculty/trainees to lead these groups. Adopting a model wherein a seasoned group of physician facilitators without primary training in the subject matter under discussion is also appropriate. This approach is used by many medical schools with master educators longitudinally leading small groups. Future studies should assess faculty satisfaction and opinion with the flipped classroom method.

\section{Flexibility and Accessibility of the Flipped Classroom Model}

Additional strengths to the flipped classroom model are the model's flexibility and accessibility. The short videos are divided into "bite-size" pieces of information rather than full-length lectures. Education research has shown favorable results for this "bite-size" approach for information delivery for students in the current age of technology.$^{18}$ The videos also give students more control and flexibility with their schedule compared with traditional lectures. In addition, the videos are dynamic, multisensory learning tools. The technology is adaptable for the hearing impaired as closed captioning can be added to the videos as well. The increased flexibility and brief video learning format may account for the higher rates of student satisfaction with the flipped classroom.

\section{Study Limitations}

Despite the strengths of this implementation, this new approach to ophthalmology education is not without limitations. One limitation is the flipped classroom's heavy reliance on technology and access to computers, which may limit the applicability in low-technology settings. Another limitation to our study is the lack of pre-course and post-course surveys assessing the traditional classroom experience in previous years to compare with the current flipped classroom surveys. When comparing student performance on the final examination between the two cohorts, students in the flipped group were exposed to practice questions, which may have contributed to this cohort's learning and examination performance. Lastly, a selection bias may exist in pre-course and post-course survey results given student response rates ( $74.3 \%$ in pre-course survey and $37.9 \%$ in post-course survey). Students invariably suffer from survey fatigue and often do not provide feedback for a completed course when already engrossed in a new subject.

\section{Conclusion}

To the best of our knowledge, this study is the first to report on the implementation of a flipped classroom approach for a 1-week preclinical medical education course in ophthalmology. 
Performance on the pre-course knowledge assessment suggests that student baseline knowledge of ophthalmology is low, as expected, emphasizing the need for effective and efficient ophthalmic education. The flipped classroom experience was positive among two consecutive classes of second year medical students. The data demonstrate student satisfaction and outstanding student test scores. These positive results show that the flipped classroom method is an implementable and effective technique for ophthalmic medical education. Future studies should assess the longevity of the knowledge gains and whether the knowledge translates to improved care or triage of patients with ophthalmic conditions by these future physicians.

This article contains a video as additional online-only material.

Note

The study was presented at The American Academy of Ophthalmology Annual Meeting 2017.

\section{Funding}

NIH Center Core Grant P30EY014801, RPB Unrestricted Award, and Career Development Awards, Department of Defense (DOD-Grant\#W81XWH-09-1-0675), The Ronald and Alicia Lepke Grant, The Lee and Claire Hager Grant, The H. Scott Huizenga Grant, The Grant and Diana Stanton-Thornbrough Grant, The Robert Baer Family Grant, The Mark Feldberg and Emilyn Page Grant, The Jose Ferreira de Melo Grant, The Michele and Ted Kaplan Grant, and the Richard Azar Family Grant (Dr. Karp/institutional grants). The sponsors/funding organizations had no role in the design or conduct of this research.

\section{Conflict of Interest}

None declared.

\section{References}

1 Mehta NB, Hull AL, Young JB, Stoller JK. Just imagine: new paradigms for medical education. Acad Med 2013;88(10):1418-1423

2 Prober CG, Khan S. Medical education reimagined: a call to action. Acad Med 2013;88(10):1407-1410

3 Touchie C, ten Cate O. The promise, perils, problems and progress of competency-based medical education. Med Educ 2016;50(01): 93-100

4 Hurtubise L, Hall E, Sheridan L, Han H. The flipped classroom in medical education: engaging students to build competency. J Med Educ Curr Develop 2015;2:35-43

5 Prober CG, Heath C. Lecture halls without lectures-a proposal for medical education. N Engl J Med 2012;366(18):1657-1659

6 Lippa LM, Boker J, Duke A, Amin A. A novel 3-year longitudinal pilot study of medical students' acquisition and retention of screening eye examination skills. Ophthalmology 2006;113(01):133-139
7 Quillen DA, Harper RA, Haik BG. Medical student education in ophthalmology: crisis and opportunity. Ophthalmology 2005; 112(11):1867-1868

8 Shah M, Knoch D, Waxman E. The state of ophthalmology medical student education in the United States and Canada, 2012 through 2013. Ophthalmology 2014;121(06):1160-1163

9 Tune JD, Sturek M, Basile DP. Flipped classroom model improves graduate student performance in cardiovascular, respiratory, and renal physiology. Adv Physiol Educ 2013;37(04):316-320

10 Morgan H, McLean K, Chapman C, Fitzgerald J, Yousuf A, Hammoud M. The flipped classroom for medical students. Clin Teach 2015;12(03):155-160

11 Ding C, Li S, Chen B. Effectiveness of flipped classroom combined with team-, case-, lecture- and evidence-based learning on ophthalmology teaching for eight-year program students. BMC Med Educ 2019;19(01):419

12 Lin Y, Zhu Y, Chen C, et al. Facing the challenges in ophthalmology clerkship teaching: is flipped classroom the answer? PLoS One 2017;12(04):e0174829

13 Tang F, Chen C, Zhu Y, et al. Comparison between flipped classroom and lecture-based classroom in ophthalmology clerkship. Med Educ Online 2017;22(01):1395679

14 Zhu L, Lian Z, Engström M. Use of a flipped classroom in ophthalmology courses for nursing, dental and medical students: a quasiexperimental study using a mixed-methods approach. Nurse Educ Today 2020;85:104262

15 International Task Force on Opthalmic Education of Medical Students; International Council of Opthalmology. Principles and guidelines of a curriculum for ophthalmic education of medical students. Klin Monatsbl Augenheilkd 2006;223(Suppl 5): S1-S19

16 Prince M. Does active learning work? A review of the research. J Eng Educ 2004;93(03):223-231

17 Deslauriers L, Schelew E, Wieman C. Improved learning in a largeenrollment physics class. Science 2011;332(6031):862-864

18 Prensky M Teaching Digital Natives: Partnering for Real Learning. Corwin Press; 2010

19 Koh GC-H, Khoo HE, Wong ML, Koh D. The effects of problembased learning during medical school on physician competency: a systematic review. CMAJ 2008;178(01):34-41

20 Schmidt HG, Vermeulen L, van der Molen HT. Long-term effects of problem-based learning: a comparison of competencies acquired by graduates of a problem-based and a conventional medical school. Med Educ 2006;40(06):562-567

21 Lambert DR, Lurie SJ, Lyness JM, Ward DS. Standardizing and personalizing science in medical education. Acad Med 2010;85 (02):356-362

22 Albert DM, Bartley GB. A proposal to improve ophthalmic education in medical schools. Ophthalmology 2014;121(06):11571159

23 Frenk J, Chen L, Bhutta ZA, et al. Health professionals for a new century: transforming education to strengthen health systems in an interdependent world. Lancet 2010;376(9756):1923-1958

24 Lee AG, Golnik KC, Tso MO, Spivey B, Miller K, Gauthier T-M. The international council of ophthalmology: vision for ophthalmic education in an interdependent world. Am J Ophthalmol 2012; 154(04):620-624.e2

25 Clarkson JG. Training in ophthalmology is critical for all physicians. Arch Ophthalmol 2003;121(09):1327-1327 